\title{
Isolation of hazardous soil contaminated by DU (depleted uranium) from groundwater
}

\author{
R. Pusch, S. Knutsson, L. Al-Taie \& M. Shahrestanakizadeh \\ Luleå University of Technology, Luleå, Sweden
}

\begin{abstract}
Cappings of waste piles conventionally contain a drain layer over a lowpermeable clay liner composed of smectite minerals. The rate of percolation of the clay liner, once it has been largely water saturated, determines the downward migration of water into and through the underlying waste. In a desert climate, cyclic variation in the degree of hydration of the clay takes place, from desiccated to largely water saturated conditions. Clays of smectite type effectively seal off the underlying waste but the content must be low for preventing contraction and expansion causing a reduced isolation potential of the liner. Penetration of the liner, implying wetting of the waste, starts when the top liner is largely water saturated but the hydration followed by dehydration is confined to take place only to a limited depth according to the assumed wetting mechanism. The rate of wetting usually follows a log time law. For an ideal composition and density of the upper clay liner there will be no percolation and wetting of the underlying waste. This paper is focused on the mechanisms involved in hydration/dehydration of a top clay liner prepared by mixing clay and ballast material for providing a basis for design, construction and maintenance of well performing cappings.
\end{abstract}

Keywords: hazardous waste, depleted uranium, landfill, groundwater, contamination, microstructural modelling.

\section{Scope}

The present paper deals with shallow disposal of hazardous waste for which many designs have been proposed, like the one in fig. 1 . The major drawback of this solution is that water can enter and flow laterally through the waste mass causing contamination of soil and groundwater on the lee-side. A superior 
technique is to construct the landfill on the ground surface, separating it from the ground for eliminating uptake of water from below, and to equip it with a capping that minimizes uptake and percolation of water from above. This principle is being proposed for isolation of hazardous waste in the form of DUcontaminated soil in Iraq [1]. The present paper deals with the evolution of top clay liners with respect to the transient degree of hydration and to their hydraulic buffering capacity [2-4].

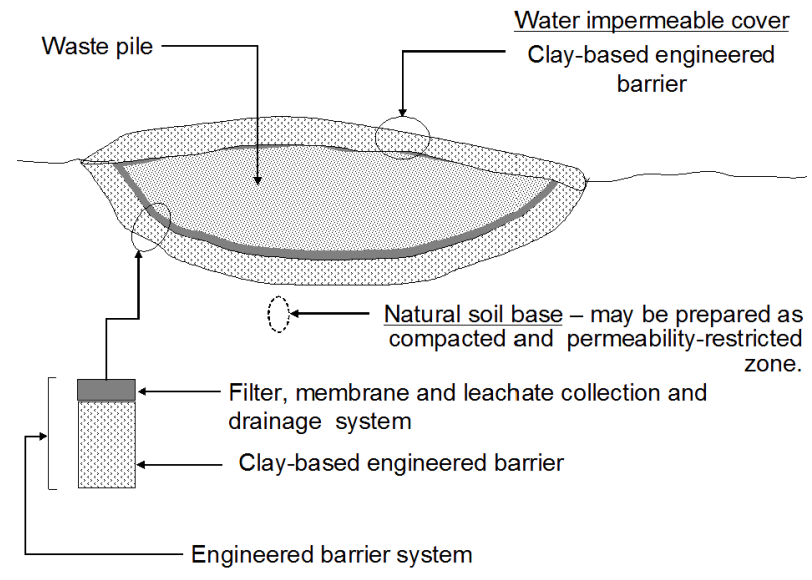

Figure 1: Traditional system of components in shallow disposal of hazardous waste [4].

The matter of cyclic hydration/dehydration caused by normal weather variations has been described and discussed earlier by various investigators leading to the belief that water retention, hysteretic phenomena and unsaturated hydraulic hysteresis phenomena play a major role, especially in thick liners. It is also understood that the boundary condition are important, like accumulation of precipitated salt and other water-driving substances at the soil surface [3, 4]. In this paper we will confine ourselves to discuss the wetting process of a smectitic top liner, the starting condition being that of an air-dry layer of smectitic soil in contact with free water temporarily contained in an overlying overburden of coarse soil that serves to provide erosion protection and to discharge rain and meltwater.

\section{Performance of clay barriers}

\subsection{Design principles}

Smectite clay is known to be an effective barrier to water since the hydraulic conductivity is very low, especially at high density, and it is therefore used extensively in cappings and bottom liners of landfills of hazardous waste. The 
clay particles consist of very thin, negatively charge lamellae between which cations and water molecules are sorbed.

The number of hydrates in the interlamellar space of the smectite species montmorillonite can be up to three for bulk densities at water saturation lower than about $1600 \mathrm{~kg} / \mathrm{m}^{3}$ and about two for bulk densities of $1900-2000 \mathrm{~kg} / \mathrm{m}^{3}$. For the very high densities $2100-2200 \mathrm{~kg} / \mathrm{m}^{3}$ there is just one hydrate layer and the suction potential at least $30 \mathrm{MPa}$. The hydraulic conductivity when sodium occupies the interlamellar space is about E-10 m/s for a density at saturation with electrolyte-free water of about $1600 \mathrm{~kg} / \mathrm{m}^{3}$. It is about E-12 m/s for a density of $1900-2000 \mathrm{~kg} / \mathrm{m}^{3}$, and drops to less than E-13 m/s for densities higher than $2100 \mathrm{~kg} / \mathrm{m}^{3}$. For saturation with $\mathrm{Ca}^{+2}$ or multivalent cations the conductivity is 5-50 times higher [3].

The very low conductivity for high densities is attractive but it is associated with a high swelling pressure. Thus, while the swelling pressure is only $300 \mathrm{kPa}$ for a density of $1600 \mathrm{~kg} / \mathrm{m}^{3}$ of $\mathrm{Na}^{+}$clay, it is $3 \mathrm{MPa}$ for a density of $1900 \mathrm{~kg} / \mathrm{m}^{3}$, and more than $20 \mathrm{MPa}$ for a density of $2100 \mathrm{~kg} / \mathrm{m}^{3}$. For saturation with $\mathrm{Ca}^{+2}$ the swelling pressure is significantly lower, i.e. $30 \mathrm{kPa}$ for a density of $1600 \mathrm{~kg} / \mathrm{m}^{3}$, $400 \mathrm{kPa}$ for a density of $1900 \mathrm{~kg} / \mathrm{m}^{3}$ and about $15 \mathrm{MPa}$ for a density of $2100 \mathrm{~kg} / \mathrm{m}^{3}$ [3]. The swelling pressure must be balanced by the overburden, i.e. the overlying erosion-protecting layer that discharges rain and meltwater. The effective pressure exerted on the clay layer by the overburden is the product of its thickness and dry density. Taking the density of the overburden as $1800 \mathrm{~kg} / \mathrm{m}^{3}$ the thickness must be $1.67 \mathrm{~m}$ if the clay liner has a density of $1600 \mathrm{~kg} / \mathrm{m}^{3}$, while the thickness must be $16.7 \mathrm{~m}$ for balancing the swelling pressure of clay with a density at water saturation of $1900 \mathrm{~kg} / \mathrm{m}^{3}$. Since thicker overburden than $5 \mathrm{~m}$ is not reasonable the swelling pressure of the clay should not exceed $900 \mathrm{kPa}$, which corresponds to a clay density at water saturation of around $1750 \mathrm{~kg} / \mathrm{m}^{3}$. This gives a layer of $\mathrm{Na}^{+}$clay a hydraulic conductivity of about $\mathrm{E}-11 \mathrm{~m} / \mathrm{s}$, which is a commonly required value.

From a practical point of view the most important measure of the hydraulic barrier effect of the clay is not the hydraulic conductivity but the transmissivity of the clay layer, i.e. the product of the conductivity and the hydraulic gradient per unit cross section area. The gradient determines the risk of piping and erosion and should not exceed $30 \mathrm{~m} / \mathrm{m}$ (meter water head per meter flow length) according to experience [4]. Applying this rule the thickness of the clay layer below an overburden of $3 \mathrm{~m}$, giving a maximum water head of $3 \mathrm{~m}$ on its upper surface, should not be less than $0.1 \mathrm{~m}$. The maximum allowable density of the clay for avoiding upheaval of the overburden would be $1650 \mathrm{~kg} / \mathrm{m}^{3}$ corresponding to a hydraulic conductivity of $5 \mathrm{E}-11 \mathrm{~m} / \mathrm{s}$ [3]. In practice, a suitable minimum thickness of the clay layer is $300 \mathrm{~mm}$, obtained by placement and compaction of clay in two campaigns. This gives a hydraulic gradient of $10 \mathrm{~m} / \mathrm{m}$ and a transmissivity of $1.5 \mathrm{E}-11 \mathrm{~m}^{2} / \mathrm{s}$, implying a percolation rate per square meter surface area of about 0.51 year and 501 per 100 years. Doubling the thickness of the clay layer reduces the hydraulic gradient to $5 \mathrm{~m} / \mathrm{m}$ and the transmissivity to $7.5 \mathrm{E}-12 \mathrm{~m} / \mathrm{s}$. The annual through-flow would be $250 \mathrm{ml}$. Making the clay layer even thicker prolongs the time for wetting and desiccation, 
which would mean that water saturation will never be reached in its lower part. This strategy will be examined and assessed in this paper in which we disregard from the impact of frost and other exogenic impact including earthquakes.

\subsection{Selection of clay material}

Theoretical modelling for finding optimal densities and thicknesses of the various components of a top liner can lead to an ideal design but in practice quite other parameters determine the choice of clay material [1]. Thus, access to and cost of suitable clay materials are decisive, which has called for extensive investigation of the performance of natural smectite-poor clays and of mixtures of suitably graded "ballast", i.e. non-expansive minerals like quartz, and smectite of montmorillonite type. The latter is in air-dry granular form with a size distribution that is suitable for achieving a desired microstructural constitution (fig. 2).
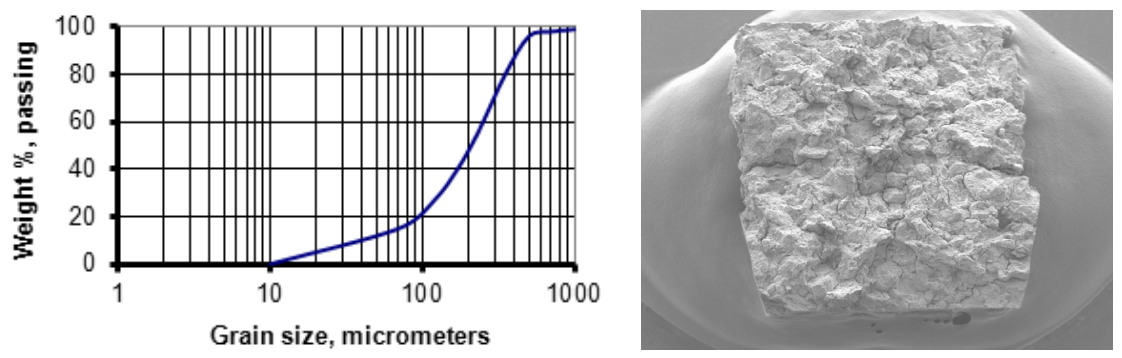

Figure 2: Typical size distribution and appearance of commercial smectite granules by scanning electron microscopy (MX-80). The edge length of the block is about $5 \mathrm{~mm}$.

\subsection{Clay microstructure}

Figure 3 shows a generalized microstructural model of clay consisting of granules.

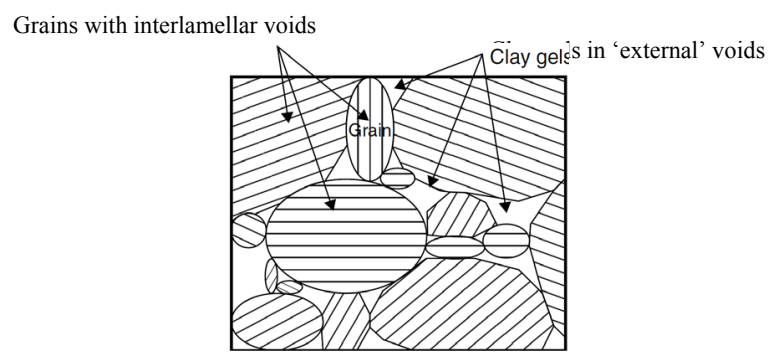

Figure 3: Arrangement of granules in compacted MX-80. The granules contain numerous small, isolated voids and billions of smectite particles [4]. 


\subsection{Clays prepared with low smectite content}

\subsubsection{General}

Although smectite-rich clays offer better isolation capability for containment of waste, smectite-poor natural clays and mixtures of smectite and ballast material can be used and they will be considered here. The principle is to create mixtures with such a granulometric composition that the space between ballast grains becomes occupied by smectite minerals [4]. Fig. 4 shows the difference between cases without clay and with smectite granules in air-dry and water saturated form. One should note that the compressibility and expandability of the mixture are low because the skeletal structure is composed of ballast grains that will carry almost all of the externally applied load. This same skeletal structure does not allow for much swelling of the pore-filling clays to occur because of the structural strength of the skeleton.

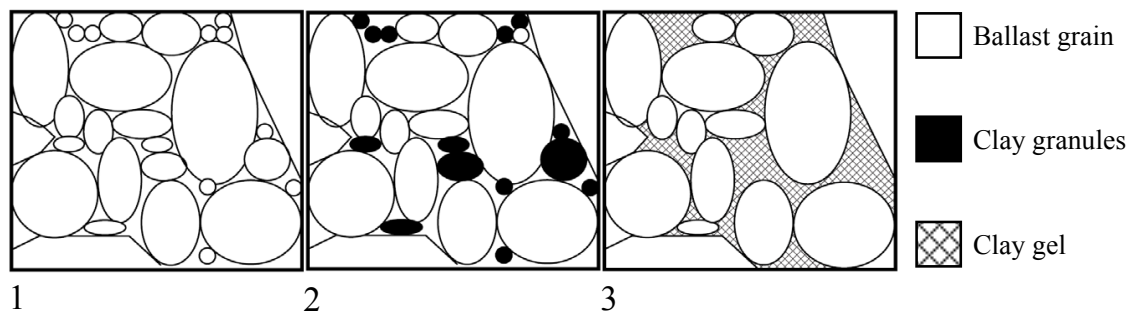

Figure 4: Microstructural constitution of soil with and without mixed-in clay component. 1) Only ballast material. 2) Smectite clay particles in the voids between ballast grains. 3) Clay hydrated and expanded in the voids [4].

The proportion of clay content is very important. As in other geotechnical contexts, a clay content exceeding about $15 \%$ means that the clay matrix becomes continuous. This will result in a situation where the ballast grains are effectively "floating" in the clay matrix. When this occurs, the properties of the clay will dominate. This is good for the hydraulic conductivity provided that the mixture can be compacted to a very dense state. For a sensible mixture that would allow for a proper development of a skeletal structure and optimum performance with respect to bulk hydraulic conductivity and compressibility, a moraine or Fuller-type ballast grain size distribution with 5 to $10 \%$ swelling clay by weight can be used.

\subsubsection{Microstructural modeling}

2.4.2.1 Geotechnical parameters Earlier work has shown that there is a relationship between the content of clay granules and the dry density of a mixture compacted to various degrees of $100 \%$ Standard Proctor density [4]. The basis for this is eqn (1), which gives the porosity $n_{s}$ of the ballast:

$$
n_{s}=1-\left(\rho_{d} / \rho_{s}\right)(1-b)
$$


where $\rho_{d}=$ dry density of the mixture, $\rho_{s}=$ density of the minerals, and $b=$ clay content (weight fraction).

Not all ballast voids can be filled with clay and the degree of clay filling can be calculated by applying eqn (2) in which the density of the clay filling is $\rho_{d b}$ and the degree of clay filling $S_{b}$ of the voids between ballast grains.

$$
S_{b}=\left[\rho_{s} / \rho_{d b}\right] /\left[\left(\rho_{s} / \rho_{d}\right) / b-\left(\frac{1}{b}-1\right)\right]
$$

Assuming the mixed soil and the clay in the respective voids to be homogeneous the relationships in table 1 for different clay contents can be derived.

Table 1: $\quad$ Semi-theoretical relationship between clay granule content, degree of compaction, and physical soil data [4-6].

\begin{tabular}{|l|c|c|c|c|c|c|}
\hline $\begin{array}{l}\text { Clay } \\
\text { content } \\
(\%)\end{array}$ & $\begin{array}{c}\text { Degree of } \\
\text { Proctor } \\
\text { comp. }(\%)\end{array}$ & $\begin{array}{c}\rho_{d} \\
\left(\mathrm{~kg} / \mathrm{m}^{3}\right)\end{array}$ & $\begin{array}{c}\rho_{\text {sat }} \\
\left(\mathrm{kg} / \mathrm{m}^{3}\right)\end{array}$ & $S_{b}$ & $n_{s}$ & $\begin{array}{c}\rho_{d b} \\
\left(\mathrm{~kg} / \mathrm{m}^{3}\right)\end{array}$ \\
\hline 10 & 100 & 2050 & 2290 & 0.40 & 0.32 & 1600 \\
\hline 10 & 87.5 & 1790 & 2130 & 0.32 & 0.40 & 1400 \\
\hline 10 & 75 & 1540 & 1970 & 0.25 & 0.49 & 1200 \\
\hline 20 & 100 & 1950 & 2230 & 0.57 & 0.42 & 1600 \\
\hline 20 & 87.5 & 1710 & 2070 & 0.50 & 0.49 & 1400 \\
\hline 20 & 75 & 1460 & 1920 & 0.43 & 0.57 & 1200 \\
\hline 50 & 100 & 1750 & 2100 & 0.81 & 0.67 & 1600 \\
\hline 50 & 87.5 & 1530 & 1960 & 0.76 & 0.72 & 1400 \\
\hline 50 & 75 & 1310 & 1830 & 0.72 & 0.76 & 1200 \\
\hline
\end{tabular}

One finds from the table that a compaction energy corresponding to $100 \%$ Standard Proctor compaction is required to give a density of $1600 \mathrm{~kg} / \mathrm{m}^{3}$ of the finally matured clay in the ballast voids. This density prevents it from collapsing should salt water enter the liner. One also observes that the degree of clay filling is low for the most clay-poor mixture and high for the most clay-rich one. For the one with only $10 \%$ clay, representing the most cost-effective mixture, the grains in the ballast skeleton are tightly connected giving it a dry density as high as $2050 \mathrm{~kg} / \mathrm{m}^{3}$ by very effective compaction. Further compaction using the most effective tools available is not possible unless the energy input is high enough to crush the ballast grains.

2.4.2.2 Hydraulic conductivity Converting the porosity of the ballast from $3 \mathrm{D}$ form to $2 \mathrm{D}$ form one gets the figure $0.32^{2 / 3}$ for the most densely compacted material with $10 \%$ clay. Taking the hydraulic conductivity to be proportional to the fraction of a cross section that is occupied by clay with a conductivity of E$10 \mathrm{~m} / \mathrm{s}$, the average net conductivity of the mixture with $10 \%$ clay content would be about $5 \mathrm{E}-11 \mathrm{~m} / \mathrm{s}$, which is substantially lower than experimental data. The reason for this is that the clay granules do not disintegrate and expand 
sufficiently deep into the narrowest space between adjacent ballast grains, a fact that has been demonstrated by numerical modeling [6]. The microstructural model geometry was in 2D and represented clay granules with a dry density of $1980 \mathrm{~kg} / \mathrm{m}^{3}$ whilst that of the ballast grains was taken to be $2650 \mathrm{~kg} / \mathrm{m}^{3}$. The dry density of the mixture was $1560 \mathrm{~kg} / \mathrm{m}^{3}$, corresponding to $2000 \mathrm{~kg} / \mathrm{m}^{3}$ at water saturation.

Fig. 5 shows successive stages in the homogenization process calculated by use of the FEM code ABAQUS using laboratory data for the expansion of the clay granules and assuming an internal friction angle of $10^{\circ}$. The ultimately reached dry density varied from 620 to $1450 \mathrm{~kg} / \mathrm{m}^{3}$, corresponding to a density at water saturation of 1400 to $1930 \mathrm{~kg} / \mathrm{m}^{3}$. The study showed that the narrowest portion of the voids between the ballast grains would not be filled with clay and that the resulting open space, that would form isolated unfilled ring-shaped zones around the contact points of ballast grains in $3 \mathrm{D}$, can only have some minor effect on the overall hydraulic conductivity. However, the heterogeneity of the clay is more important; the density of the clay would be low in the most expanded part of the clay grains, and remain high in the central parts of the granules. The risk of piping and erosion of the softest parts would be considerable.
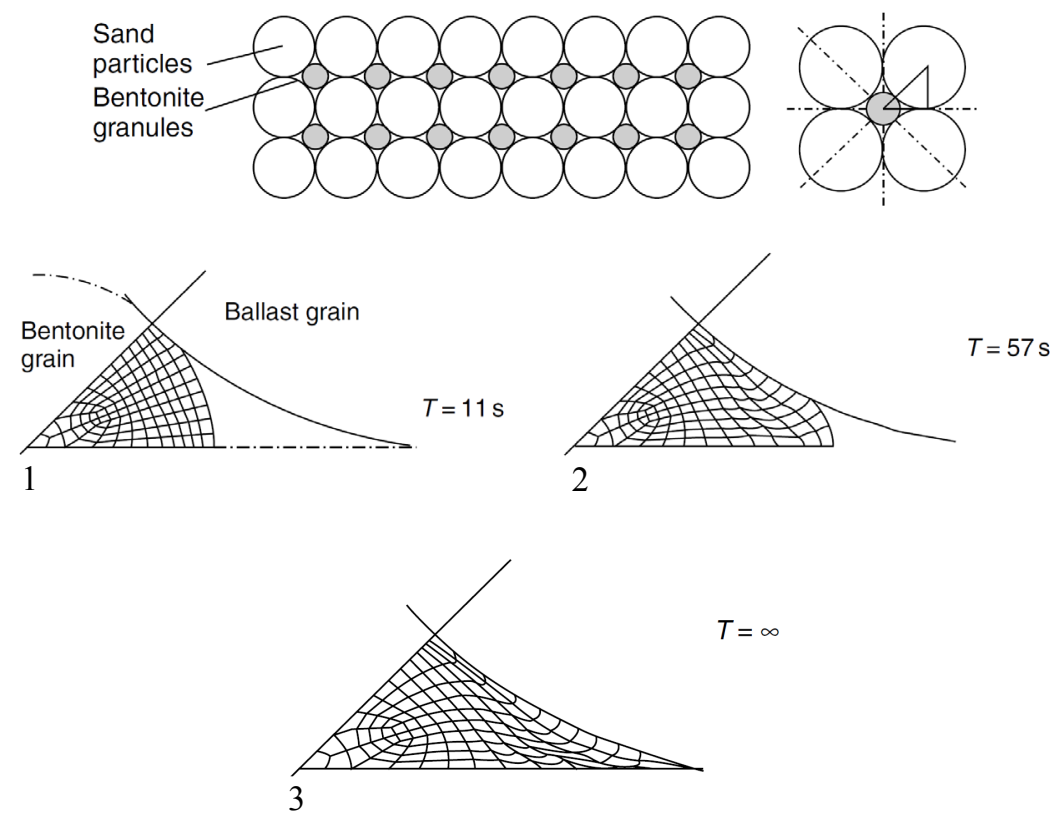

Figure 5: Maturation of mixture of 10\% smectite clay (MX-80) and ballast particles according to a 2D FEM analysis [6]. Pictures 1, 2, and 3 show the expansion of the clay between the ballast grains. The softest part in the ultimate stage has a density at saturation of 1420 $\mathrm{kg} / \mathrm{m}^{3}$, and $1930 \mathrm{~kg} / \mathrm{m}^{3}$ in the densest part. $\mathrm{T}$ is time in seconds. 
It is evident that the prudent course of action is to use very fine-grained clay when the amount of clay added to the ballast is small. The impact of the grain size distribution of both ballast and clay particles indicates that both types of materials should conform to the Fuller parabolic curves to minimize the size and volume of unfilled voids.

\subsection{Hydration/dehydration}

\subsubsection{Water inflow}

Water uptake of smectitic clays takes place by penetration if the density is low and by diffusive migration if it is high. Large-scale tests have shown that inflow of water into soft fills of clay granules takes place in a finger-like manner as illustrated in fig. 6. For low inflow rates, generating low pressure at the inflow point, a small hydraulic wedge is formed but it remains stable by being blocked by the confining pellets that sorb water from the wedge. Many more small wedges tend to grow in different directions but they all stagnate because of the successively tighter clay gel around them. The water pressure is thereby raised and a larger hydraulic wedge evolves and propagates. This high-pressure case is reached after sufficiently long time independently of the inflow rate, which is in fact also the conclusion from full-scale tests [6].
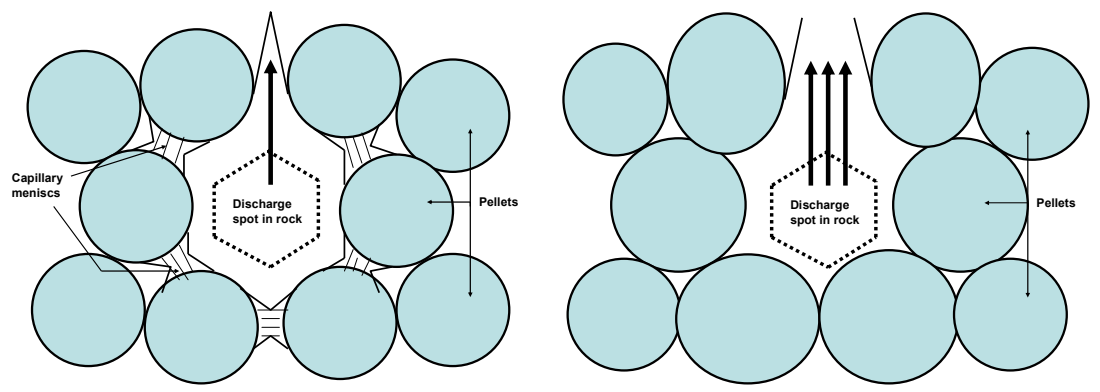

Figure 6: Penetration of water into a fill of expandable granules. Left: first stage causing expansion and coherence of the granules and initiation of water wedge. Right: stage with expanded pellets and pressure rise causing growth of water wedge forming a channel.

The overall conclusion from the tests was that a critical state with local piping and erosion will take place in soft fillings even for very low inflow rates. The same phenomenon can occur also in mixed clay/ballast fills because of the low density of the clay in the ballast voids. Assuming, conservatively, that there is a threshold inflow rate of 0.11 per minute and inflow spot, this would roughly correspond to an inflow of tens to hundreds of liters per minute and square meter. Such conditions can be reached for the common case of covering the clay layer with welded plastic membranes in which holes can form and to which large amounts of water can be directed. Assuming $10 \mathrm{~mm}$ rain to fall in one hour and water from $1000 \mathrm{~m}^{2}$ being discharged through a single hole in the plastic 
membrane it would correspond to an inflow rate of 0.171 per minute, which will cause piping and erosion of the clay layer. This situation will not appear in practice with the clay layer covered by an overburden that is very fine-grained at the contact with the clay because of its flow-distributing function.

\subsubsection{Hydration by diffusive water transport}

There are comprehensive studies of the mechanisms involved in the hydration of smectitic clay under low water pressure [4]. In fact, common oedometer testing of smectitic clay in geotechnical laboratories provides information on the rate of water saturation that precedes the steady-state percolation for determining the hydraulic conductivity, and the hydration has generally been interpreted as a diffusion process [4]. Such tests take only a few weeks for standard sample sizes but there are experiments that have lasted for several years that show the same.

Fig. 7 shows the distribution of the water content in a 6 year column test for determination of the hydration rate of a mixture of $10 \%$ smectite-rich clay and Fuller-type ballast compacted to a dry density of $1450 \mathrm{~kg} / \mathrm{m}^{3}$. The initial water content was $2.3 \%$ and the water to be taken up was distilled and doped with a low concentration of formaline for avoiding algae growth. The column was $2 \mathrm{~m}$ high and $300 \mathrm{~mm}$ in diameter. Water was filled to maintain a constant water table $1 \mathrm{~m}$ over the clay, which was covered with $0.1 \mathrm{~m}$ silt and $0.5 \mathrm{~m}$ sand for simulating an overburden. The experiment, which started in 1987 and terminated in 1993, has been reported earlier [4]. It indicated diffusive wetting of the larger part of the clay pile but no water uptake in the lower $50 \mathrm{~mm}$ part even after 6 years. The convex curve shape down to half the clay height is believed to have been caused by dominant inflow under the prevailing water head, while the rest of the curves indicates diffusive wetting. The evaluated diffusion coefficient was about $3 \mathrm{E}-10 \mathrm{~m}^{2} / \mathrm{s}$, which agrees well with the corresponding coefficient values derived from oedometer tests. Using coefficients of this order complete water saturation of test column would take at least 100 years. Under real conditions the cyclic desiccation/wetting conditions in desert climate of a clay liner with a

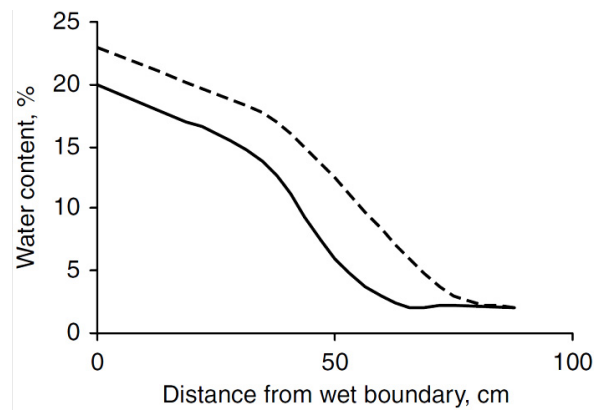

Figure 7: Water content distribution in 6 year column test of mixed clay $(10 \% \mathrm{MX}-80)$ and ballast with $10 \mathrm{kPa}$ water pressure acting on the clay. The lower curve represents the condition after 4 years and the upper the state after 6 years. 
thickness of the tested type would lead to a variation in distribution and magnitude of the water content but not to complete water saturation. A thickness of the clay liner of only $300 \mathrm{~mm}$ would most probably not give complete water saturation quicker than for the thicker one under arid conditions. However, for practical reasons and considering safety margins a somewhat thicker layer is recommended.

Considering the inhomogeneous physical state of the clay in the voids between ballast grains exhibited by the theoretical modeling it is highly probable that the early hydration in the column tests had the form of finger-like penetration. A more uniform migration of water into a smectitic liner would be obtained if all the grains contain clay, still maintaining a low total clay content. This would give a more comprehensive wetting by uniform expansion of each soil element and lead to a more uniform density of the liner. This strategy has been applied in recent landfill projects providing technical/economical optimization by using natural slightly smectitic clays, which are available in most countries exemplified by Lithuania and Germany, where they form large quantities of uniformly composed, easily exploitable beds. Experience from field compaction of such clay shows that densities of the same order as for mixtures of smectite-rich granules and ballast grains can be obtained by using vibrating rollers of sheep-foot or pad-foot type. For either of these materials dry placement and compaction should be made for avoiding over-saturation in the compaction stage (fig. 8), for delaying hydration, and for saving cost [4].

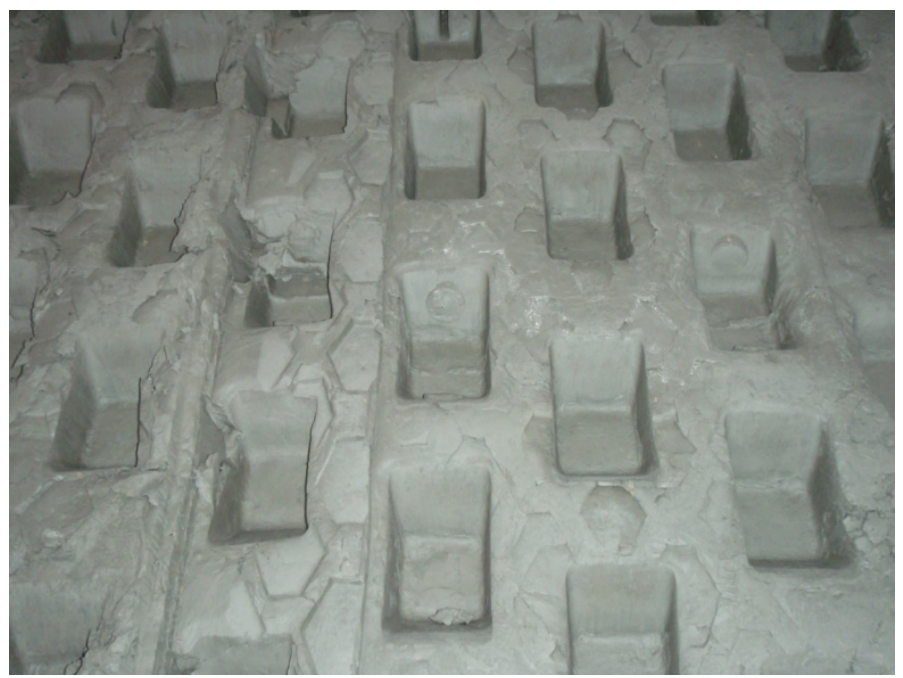

Figure 8: Appearance of padfoot-compacted expandable clay placed in the form of slightly dried natural material. The wet surface indicates that the clay was compacted to complete water saturation. It was, however, perfectly homogeneous and no grains or chunks can be seen [8]. 


\section{Discussion and conclusions}

Landfills of hazardous waste material conventionally contain a low-permeable clay-based top liner covered by a drain layer that also serves to exert sufficient pressure on the clay layer for balancing its expandability and protecting it from being eroded. If the clay liner can be composed and constructed so that water will not penetrate it and enter the underlying waste the desired state of perfect isolation of the waste would be reached. The conditions for this are good in arid areas like the southern parts of Iraq where DU-contaminated, hazardous soil and armed tools and vehicles remaining from recent wars should be isolated in landfill form.

The main issue is whether one can find a design that makes the top cover of the waste fulfil the various criteria that are defined, i.e. 1) to maintain its coherence under the expected conditions of cyclic wetting and drying and, 2) to become so slowly and uniformly wetted that desiccation in drier seasons brings the physical constitution back to the initial, 3) to find suitable local clay material at very low cost, and 4) make construction with required accuracy. To this comes that suitable coarse-grained material of boulder and block size and also fine silt/sand for filter construction must be found for constructing the overburden.

One concludes from the present pilot study that:

- the rate of percolation of the clay liner, once it has been largely water saturated, determines the downward migration of water into and through the underlying waste, which is DU-contaminated sandy soil, and down to the bottom liner. If penetration of water down into the waste can be hindered no contaminating elements from the waste can enter the groundwater by water flow or diffusion and no problems with gas production that can affect the top liner will take place. Construction of a tight bottom liner will not be required,

- in desert climate the best possibility to avoid penetration of rainwater through the clay liner is offered by very slow hydration with intermittent desiccation of the upper clay liner. This creates local cyclic variation in degree of wetting from desiccated to largely water saturated conditions of the clay in the top liner,

- the criteria defined can be fulfilled by mixtures of a small amount of smectite-rich clay and suitably graded non-expanding ballast grains, preferably quartz material since it is inert in practice. With a fine-grained filter separating the upper drain layer from the upper clay liner for preventing clay particles to migrate out from it, the uptake of water of the liner will be uniform and driven by its suction potential. The basic idea of using ballast with a gradation that makes the grains form a stable network with clay in the voids the desired conditions of a non-expanding and incompressible liner material is the key point,

- using natural smectite-poor clay instead of mixtures of smectite-rich clay and ballast will improve the homogeneity and tightness of the liner but technical/economical optimization requires comparison of the cost of such liner material with that for mixed material considering also the expenses for mixing and homogenization. 


\section{References}

[1] Laith Al-Taie, 2011. Proposed Site Selection Criteria for Hazardous Waste Landfills in Iraq. Proc. Int. Workshop on Hazardous Landfills. Luleå University of Technology, November 2011.

[2] Nakano, M., Yong, R.N., 2011. Cyclic water transfer in the top soil of a landfill. Proc. Int. Workshop on Hazardous Landfills. Luleå University of Technology, November 2011.

[3] Pusch, R., Kihl, A., 2004. Percolation of clay liners of ash landfills in short and long time perspectives. Waste Management \& Research, Vol.22, No.2 (2204). ISSN 0734-242X (pp. 71-77).

[4] Pusch, R., Yong, R.N., 2006. Microstructure of Smectite Clays and Engineering Performance. Taylor and Francis, London and New York (ISBN: 0-415-36863-4).

[5] Pusch, R., 1985. Final Report of the Buffer Mass Test - Volume III: Chemical and Physical Stability of the Buffer Materials. Stripa Project Technical Report 85-14, Swedish Nuclear Fuel and Waste Management Co (SKB).

[6] Börgesson, L., 1993. Swelling and homogenisation of bentonite granules i buffer and backfill. Swedish Nuclear Fuel and Waste Management AB (SKB). AR 95-22. Stockholm.

[7] Dixon, D, 2008. Tests to determine water uptake behaviour of tunnel backfill (Baclo Tests at Äspö). SKB Report R-08-134. SKB, Stockholm.

[8] Pusch, R., Malmborg, B., Strandljung, K., 2011. Example of construction of very tight clay liners - the Högbytorp case. Proc. Int. Workshop on Hazardous Landfills. Luleå University of Technology, Nov. 2011. 